\title{
Study on the Teaching of Chinese Language and Literature in the Context of New Curriculum
}

\author{
Meihan $\mathrm{Ji}^{1 \text {, a }}$ \\ ${ }^{1}$ Teacher's College, Beihua University, Jilin 132013, China. \\ ameihan_ii@126.com
}

Keywords: Chinese language and literature teaching, new curriculum, Chinese classic poem.

\begin{abstract}
With the new course teaching of Chinese has already been launched in domestic college and university, the implementation of new teaching material are a fortune for Chinese teachers as well as for Chinese teaching which needs they turn their ideas of Chinese classic poem teaching to new model. Chinese classic poem teaching is discussed to improve students' traditional cultural knowledge and to enjoy the beauty of literature. The multimedia and network are applied as effective Ways to improve the quality of Chinese language and literature teaching.
\end{abstract}

\section{Introduction}

The long-standing traditional Chinese teaching model, with the current perspective, not only tied the student's personality, but also allow teachers to live very tired, whether teachers or students are looking forward to the curriculum reform. Now, the new language curriculum standards finally came into being. In order to effectively promote the curriculum reform, the state has invested a lot of manpower, material and financial resources, the development of standards, the preparation of teaching materials, organization and implementation. Can be said that the whole country from top to bottom vigorous, such as fire tea. The most obvious feature of the new curriculum, which has been hailed as the "educational revolution", is to emphasize "student-oriented" and change the traditional concept of teacher-centered in the past. Center, to cultivate students the ability of self-exploration, students develop the ability to identify problems, develop students 'ability to analyze and solve problems, and cultivate students' innovative spirit.

The new curriculum reform will not solve the long - standing problems in some courses, but the new curriculum reform is not a good medicine to solve all educational problems. We should not only dialectically recognize the new curriculum reform, the implementation of the new curriculum, but also pay attention to some issues. First of all, we must dialectically recognize the status of teachers and students in teaching. The new curriculum reform emphasizes the students' subjectivity and individuality, which is correct. However, if we deny the status and role of teachers, it is a fundamental violation of the law of education. The subjectivity and individuality of students are inseparable from the cultivation and shaping of teachers, teachers in education and teaching in the dominant position can not be shaken. Secondly, we should dialectically recognize the relationship between learning and learning. Found that learning and learning are important learning methods. The new curriculum reform emphasizes the people's discovery learning, emphasizing the exploration of knowledge and students' interest in learning, etc., is undoubtedly important. But if we only found that sexual learning, not to accept the learning, teachers ignore the system of teaching knowledge, ignoring the students a comprehensive systematic knowledge of learning and mastery, the results will be cultivated in the learning initiative and creativity, while reducing Students' learning efficiency, and even to a certain extent, the destruction of human knowledge of the system to learn and master. Of course, whether the new curriculum reform will eventually achieve actual results, but also the test of practice. But the whole society to pay attention to the reform of the new curriculum, while improving the overall quality and level of teachers, in particular, to help teachers establish a scientific concept of education, the implementation of the new curriculum reform is undoubtedly the most important. Otherwise, no 
matter how good the new curriculum, teacher education is obsolete, and the result can only wear new shoes to take the old road.

On the one hand, it is beneficial to further understand and study the new curriculum requirements in the teaching practice, on the other hand it is from the specific problems of the starting point of the teaching of classical poetry, The specific teaching activities of ancient poetry appreciation - so as to implement the requirements of the new curriculum to explore the actual teaching process of appreciation of classical poetry teaching the specific operation for the appreciation of classical poetry teaching research and practice to contribute. Around the new curriculum in the context of the teaching of classical poetry.

\section{The Teaching Mode under the Background of New Curriculum}

The transformation of Chinese teaching ideas, including the emphasis on humanistic language teaching, the emphasis on language literacy, emphasis on aesthetic education. The new curriculum standard for the appreciation of ancient poetry teaching put forward higher requirements and more favorable conditions. It is because the ancient poetry has the feeling beauty, the artistic beauty, the language beauty, the music beauty and so on, therefore it has the intense literary nature, for the classical poetry teaching, is must fully utilize the poetry literature the beauty, "," Baptist "," thorn "," mention "role, so that students are aesthetic education, cultural accomplishment and cultural literacy to be improved. On the one hand, this is the requirement of the new curriculum standard, on the other hand, it is precisely because of the "literary" nature of ancient poetry teaching, which makes it be able to play its own characteristics, Highlighting the aesthetic education, is conducive to enhancing the students' cultural accomplishment and cultural accomplishment.

In the course of specific teaching practice, the teaching of classical poetry should emphasize the problem of aesthetic education and humanistic education. The ancient poetry teaching should adapt to the requirements of the times, break through the traditional framework and make new interpretation of classical poems. In order to make the students be subjected to aesthetic education and humanistic education through aesthetic study and traditional culture, the students' To enhance the personality to be purified, towards a higher spiritual pursuit and realm of life, to the excellent traditional culture to guide people, inspire people and the purpose of nurturing people. The main way is to let students in the reading of ancient poetry in the comprehend into the works of human beauty, natural beauty, understand the harmonious relationship between man and nature, while understanding the beauty of language and beauty of poetry, New interpretations should be made under new historical conditions. In the process of learning ancient poetry, a very important place is to cultivate the students for classical poetry feelings, to develop their sense of language, and language training to a greater extent depends on a large number of extra-curricular reading.

To Make Full Use of Modern Teaching Technology in Ancient Poetry Teaching. Multimedia and network technology into the classroom, is the modern educational technology into the concrete performance of the classroom, is a very beautiful modern teaching side. Ancient poetry teaching must use the new teaching methods, with the help of new teaching equipment. Multimedia in a fresh and vivid way to the text of poetry to the students in front of the text, sound, picture and other comprehensive teaching courseware to students, so that students in a comprehensive teaching courseware to accept more traditional forms of modern culture. The network provides more knowledge resources for students 'extracurricular learning and reading, and provides more convenient and quick way for the students to occupy and use the information, and expand the space of students' autonomous learning. The new curriculum standard puts forward higher requirements for the teaching of ancient poetry appreciation, provides more room for development, and also offers the possibility to introduce more modern teaching techniques. However, in the practice of ancient poetry teaching, To recognize that poetry is to express language as a means of expression to provide people with emotional experience and aesthetic experience, so the teaching should be the main text of poetry, to avoid the use of modern multimedia and network technology to dilute the reading and appreciation of the text , To avoid the form of teaching is greater than the content, more than content, to avoid the 
diversification of the form of teaching into a pattern, thus forgetting the original purpose of literary education. On the one hand, these problems are still prevalent in reality, on the one hand is the need for us to continue to study and explore.

How to improve the teaching of ancient poetry appreciation, obviously there are many issues worthy of further study, such as how to prepare lessons, how to carry forward the enthusiasm of students in learning and subjectivity, how to make teaching theory research in practice to be implemented, These issues require us to further efforts in both theory and practice. At the same time, we must realize that deepening the curriculum reform not only to further study and solve the new problems in the field of curriculum, but also to overcome the curriculum reform on the existing educational tendency. If education reform, apart from or ignore the reality of the social development of the information age, put aside the changes in people's ideas and behavior patterns during the social transition period, only from the education itself to discuss the problems of education, it is empty and divorced from reality, To obtain an effect.

\section{Aesthetic Education and Humanistic Education Should Be Emphasized in Appreciation Teaching}

The new curriculum standards for the concept of language teaching, teachers, teaching methods and other issues have raised newer and higher requirements, how in the specific teaching practice for the new curriculum standards to improve the appreciation of ancient poetry teaching, the problem involves teaching All aspects of the process. Here, I first explore the ancient poetry teaching to highlight the aesthetic education and humanistic education of this problem.

The ancient poetry teaching should adapt to the requirements of the times, break through the traditional framework and make new interpretation of classical poems. In order to make the students be subjected to aesthetic education and humanistic education through aesthetic study and traditional culture, the students' To enhance the personality to be purified, towards a higher spiritual pursuit and realm of life, to the excellent traditional culture to guide people, inspire people and the purpose of nurturing people.

The classical poetry in middle school Chinese class is the classic literary works which have been passed by the test of history. They have been able to become classics because these poems have strong literary and ideological character and surmount the limitation of time and space. The study of these classic works will undoubtedly make the students be affected by beauty and infection, improve their level of literary appreciation, and have a better understanding of Chinese traditional culture, resulting in deeper feelings. However, any work is able to withstand the test of time, enduring in the long history, but at the same time has a certain age, its reading and understanding with the changes of the times. In the new social and historical conditions, with the change of people's mental outlook and thoughts and feelings, with the changes of social cultural psychology and aesthetic concepts, we must face the problem of the teaching of appreciation of ancient poems for the new curriculum. The classical poetry can be accepted by the students because of the new reading and explanation of the classical poetry, which can make it have the flavor of the times and pass it on to the students.

\section{Utilizing Modern Educational Technology to Serve Classical Poetry Appreciation}

The development of modern science and technology has had more and more profound influence on the social life, the science and technology factor penetrates into the social life aspects. As a part of people's social life and ideology, education and teaching, not only content but also form, are more and more influenced by modern science and technology. This will bring impact to our school education, bring profound changes to education idea and education form. . Because of the deep-rooted traditional Chinese teaching concept, the mainstay of the students in the school has not really been reflected, and the teaching method centered on the teacher's teaching is still prevalent. In the future, with the extensive application of modern educational technology, the traditional classroom teaching will develop into class teaching, group teaching (group media teaching method, micro teaching 
method), individual teaching and network teaching (interactive network teaching, distance education) Of the situation, so that teachers will truly establish a "teaching-led, learning as the main" teaching concept. At the same time, the traditional "teacher-student" teaching model will also be transformed into "teacher-media-student" mode. In addition, the role of teachers and students is also required to change, that is, from the traditional education process, the teacher simply impart knowledge and instill into the meaning of student initiative to build a facilitator and facilitator, students also by the knowledge of the "container" Into the "acquirers" of knowledge, from external stimuli to passive recipients and knowledge infusion into the main body of information processing and knowledge of the active constructor.

\section{Conclusion}

The use of multimedia and network teaching is now an important form of teaching, it is the modern information society on the school education is a necessary requirement, but also the impact of scientific and technological means to people's lives more and more proof. At the same time, it also reflects the modern education, especially school education to the trend of openness and democracy. Secondary education, including our discussion of ancient poetry appreciation teaching, full use of multimedia and network is also the spirit of the new curriculum in practice a concrete manifestation. However, the use of multimedia and network teaching will lead to the emergence of some problems, the new curriculum standards for the teaching of ancient poetry to teach a higher demand, providing more room for development, but also for the introduction of more modern teaching techniques to provide a However, it should be noted that in the practice of ancient poetry appreciation teaching, it is necessary to realize that poetry is a means of expression to provide people with emotional experience and aesthetic experience, so in the teaching of poetry should be the main text, To avoid the use of modern technology such as multimedia and network to dilute the reading and appreciation of the text, to avoid the form of teaching is greater than the content, more than content, to avoid the diversification of the form of teaching into the pattern, thus forgetting the original purpose of literature and education.

\section{References}

[1] Jiang Honggen. A Probe into Chinese Teaching Strategies in the Context of New Curriculum. Contemporary Education Science. 2004, No. 22, 55-57.

[2] Guo Zhengping. Establish a large language view, open language teaching, Journal of Kaifeng Institute of Education, 2003 the third period, 64-69.

[3] Zhang Jinbo. X21 century middle school Chinese curriculum and teaching reform, Journal of Anqing Teachers College (Social Science Edition), 2014 the fifth period, 126-127.

[4] Tao fine roots. From the perspective of teachers on Chinese teaching reform, Jiangxi Education and Research, 2003, 1, 2, 68-70.

[5] Car Po Yan. The Requirements of Chinese Teaching Reform in Middle Schools, Journal of Xi'an Institute of Education, No.4, 2003, 66-67.

[6] Wu Ji Lei. On the influence of teaching technology modernization on Chinese teaching, Vocational Education Forum, 2003 the tenth period, 57.

[7] Sun Ruiying. The use of modern teaching methods to promote language teaching reform, Kaifeng Institute of Education, 2004 the third period, 59-60.

[8] Wu Qiuxia. To multimedia technology as the support for the reform of language teaching to create a good teaching environment, health vocational education, 2003 the seventh period, 26-28. 